\title{
Pengaruh Kotoran Organik pada Pasir Kasar Sungai Batanghari terhadap Kuat Tekan Mortar
}

\author{
${ }^{1}$ Maidita Ajizah Prastika, ${ }^{2 *}$ Suhendra, ${ }^{3}$ Wari Dony \\ ${ }^{1,2,3}$ Teknik Sipil Univ. Batanghari \\ Correspondence email: suhendra_domas@yahoo.com
}

\begin{abstract}
Abstrak. Kandungan organik adalah bahan-bahan organik yang terdapat di dalam pasir dan menimbulkan efek yang merugikan terhadap mutu mortar atau beton. Kadar bahan organik dalam agregat halus akan memperlambat proses pengikatan semen, dan juga akan memperlambat perkembangan kenaikan mutu beton/mortar. Mortar adalah campuran semen, pasir, dan air yang memiliki persentase yang berbeda. Benda uji mortar ada 3 variasi perlakuan yaitu pasir tidak dicuci, pasir yang dicuci dengan air, dan pasir yang direndam $\mathrm{NaOH} 3 \%$, Sumber pasir dari sungai Batanghari Desa Sembubuk Kec. Jambi Luar Kota, Kab. MuaroJambi, Jambi. Kategori pasir kasar berdasarkan British Standard dan ASTM C33. Penelitian ini bertujuan mendapatkan kadar kotoran organik yang terdapat pada pasir kasar sungai Batanghari dan Mengetahui pengaruh pasir kasar sungai Batanghari terhadap kuat tekan mortar. Metode pelaksanaan mengacu pada SNI 03-6825-2002 tentang Metode Pengujian Kekuatan Tekan Mortar Semen Portland. Benda uji mortar berbentuk kubus dengan ukuran 5x5x5 cm. Dari hasil pengujian kotoran organik pada pasir kasar sungai Batanghari yaitu pada pasir tidak dicuci di angka 5, pasir yang dicuci dengan air di angka 3 dan pasir yang direndam dengan $3 \% \mathrm{NaOH}$ di angka 1 pada organic plate. Hasil penelitian menunjukkan bahwa nilai kuat tekan mortar rata-rata 28 hari pasir dicuci dengan air lebih besar 6,67\% dari pasir tidak dicuci, untuk kuat tekan rata-rata 28 hari pasir yang direndam dengan $\mathrm{NaOH} 3 \%$ lebih besar $24,19 \%$ dari pasir tidak dicuci.
\end{abstract}

Kata kunci: Pasir Kasar; Kotoran Organik; Mortar; Kuat Tekan

\section{PENDAHULUAN}

Mortar didefinisikan sebagai campuran material yang terdiri dari agregat halus (pasir), air, dan semen Portland dengan komposisi tertentu menurut SNI 03-6825-2002

Fungsi utama mortar adalah menambah lekatan dan ketahanan ikatan dengan bagian-bagian penyusun suatu konstruksi baik yang bersifat structural maupun nonstruktural. Penggunaan mortar untuk konstruksi yang bersifatt struktural misalnya mortar pasangan batu belah untuk stuktur pondasi, sedangkan yang bersifat nonstruktural misalnya mortar pasangan batu bata untuk dinding pengisi.

\section{Flow Mortar}

Flow merupakan tolak ukur dari sifat kebasahan pada mortar (fluidity). Konsistensi ini sangat bergantung pada proporsi dan sifat-sifat dari campuran mortar.

\section{Gradasi Agregat Halus}

Gradasi agregat adalah distribusi ukuran butiran dari agregat. Sebagai pernyataan gradasai dipakai nilai persentase dari berat butiran yang tertinggal atau lewat di dalam suatu susunan ayakan. Susunan ayakan itu adalah ayakan dengan lubang : $76 \mathrm{~mm}, 38 \mathrm{~mm}, 19 \mathrm{~mm}, 9,6 \mathrm{~mm}, 4,80 \mathrm{~mm}, 2,40 \mathrm{~mm}, 1,20 \mathrm{~mm}, 0,60 \mathrm{~mm}, 0,30 \mathrm{~mm}$, dan $0,15 \mathrm{~mm}$.

Menurut British Standard agregat halus dikelompokkan dalam empat zona seperti dalam tabel berikut ini:

Tabel 1. Syarat batas gradasi agregat halus menurut British Standard

\begin{tabular}{ccccc}
\hline \multirow{2}{*}{ Lubang Ayakan (mm) } & \multicolumn{4}{c}{ Persen Butiran Yang Lewat Ayakan } \\
\cline { 2 - 5 } & $\begin{array}{c}\text { Zona I (Pasir } \\
\text { Kasar) }\end{array}$ & $\begin{array}{c}\text { Zona II (Pasir } \\
\text { Agak Kasar) }\end{array}$ & $\begin{array}{c}\text { Zona III (Pasir } \\
\text { Agak Halus) }\end{array}$ & $\begin{array}{c}\text { Zona IV (Pasir } \\
\text { Halus) }\end{array}$ \\
\hline 10 & 100 & 100 & 100 & 100 \\
4,8 & $90-100$ & $90-100$ & $90-100$ & $95-100$ \\
2,4 & $60-95$ & $75-100$ & $85-100$ & $95-100$ \\
1,2 & $30-70$ & $55-90$ & $75-100$ & $90-100$ \\
0,6 & $15-34$ & $35-59$ & $60-79$ & $80-100$ \\
0,3 & $5-20$ & $8-30$ & $12-40$ & $5-50$ \\
0,15 & $0-10$ & $0-10$ & $0-10$ & $0-15$ \\
\hline
\end{tabular}

Sumber : British Standard

Menurut ASTM C33, Agregat halus harus mempunyai susunan besar butir dalam batas-batas pada tabel berikut ini: 
Tabel 2. Syarat batas gradasi agregat halus menurut ASTM C33

\begin{tabular}{cc}
\hline Ukuran Saringan $(\mathbf{m m})$ & Persentase Lolos Kumulatif $(\boldsymbol{\%})$ \\
\hline 9,5 & 100 \\
4,75 & $95-100$ \\
2,36 & $80-100$ \\
1,18 & $50-85$ \\
0,60 & $25-60$ \\
0,30 & $5-30$ \\
0,15 & $0-10$ \\
\hline
\end{tabular}

Sumber : ASTM C-33 (Specification For Concrete Aggregates)

\section{Modulus Kehalusan}

Modulus halus butir ini definiskan sebagai jumlah persen kumulatif dari butir-butir agregat yang tertinggal diatas satu set ayakan dan kemudian dibagi seratus. Susunan lubang ayakan tersebut adalah $76 \mathrm{~mm}, 38 \mathrm{~mm}$, $9,60 \mathrm{~mm}, 4,80 \mathrm{~mm}, 2,40 \mathrm{~mm}, 0,60 \mathrm{~mm}, 0,30 \mathrm{~mm}$, dan $0,15 \mathrm{~mm}$.

Menurut ASTM C-33 (Specification For Concrete Aggregates) dimana nilai modulus halus butir antara 2,3- 3,1 dengan variasi butir sesuai standar gradasi.

\section{Air}

Kualitas air mempengaruhi kekuatan pasta dan mortar. Air untuk pembuatan dan perawatan pasta dan mortar tidak boleh mengandung minyak, semen alkali, garam, bahan-bahan organik, atau bahan lain yang dapat merusak pasta dan mortar.

\section{Kandungan Organik}

Bahan organik yang terdapat dalam agregat beton/mortar biasanya berasal dari hasil penghancuran zat-zat tumbuhan, terutama asam tenin dan derivatnya yang berbentuk humus dan lumpur organik.

Bahan organik ini banyak terdapat dalam agregat halus atau pasir. Kadar bahan organik dalam agregat halus akan memperlambat proses pengikatan semen dan juga akan memperlambat perkembangan kenaikan kekuatan beton/mortar.

Agregat halus atau pasir tidak boleh mengandung bahan organik terlalu banyak, yang harus dibuktikan dengan percobaan warna dari abrams, yang lebih popular dengan pengujian Abrams Harder Peraturan Beton Indonesia (PBI. 71, hal.23). Pengujian dilaksanakan dengan menetralkan organik yang ada dalam pasir memakai soda api (NaOH $3 \%)$, warna cairan yang terjadi dibandingkan warna standar, jika warna cairan yang terjadi sama atau lebih muda dari warna standar, menunjukkan bahwa kadar bahan organik rendah, pasir dinyatakan baik, dan sebaliknya.

Tabel 3. Kotoran organik dalam agregat halus berdasarkan Abrams Harder

\begin{tabular}{cll}
\hline Standar Warna & \multicolumn{1}{c}{ Warna Cairan } & \multicolumn{1}{c}{ Pasir } \\
\hline 1 & Tidak ada warna sampai dengan warna kuning muda & Dapat dipakai \\
2 & Kuning muda & Kadang-kadang dipakai \\
3 & Merah kekuning-kuningan & Digunakan untuk lantai biasa \\
4 & Coklat kemerah-merahan & Tidak dapat digunakan \\
5 & Coklat tua & Tidak dapat digunakan \\
\hline
\end{tabular}

Sumber SNI 2816-2014

\section{METODE}

Mortar yang diteliti terdiri dari campuran semen Portland Composite Cement (PCC), air PDAM di Universitas Batanghari, dan agregat halus dari Sungai Batanghari.

Agregat halus yang digunakan adalah pasir zona I yang terdapat sungai Batanghari. Pembuatan sampel, pemeliharaan, dan pengujian sampel dilakukan di Laboratorium Teknik Universitas Batanghari Jambi.

Pengujian mortar dilakukan untuk tiga perlakuan pasir, yaitu pasir tidak dicuci, pasir yang dicuci dengan air, dan pasir yang di rendam $\mathrm{NaOH} 3 \%$.

Benda uji berbentuk kubus dengan ukuran $5 \mathrm{~cm} \times 5 \mathrm{~cm}$ x $5 \mathrm{~cm}$ berjumlah 18 buah. Untuk masingmasing perlakuan pasir, dibagi menjadi 6 benda uji pada masing-masing umur pengujian.

1. Pasir tidak dicuci

Dalam pembuatan benda uji mortar, pasir yang telah diambil, terlebih dahulu di keringkan tanpa di cuci ataupun dibersihkan dengan larutan $\mathrm{NaOH} 3 \%$ kemudian di saring sesuai gradasinya.

2. Pasir yang dicuci dengan air 
Dalam penelitian mortar, pasir yang sudah di saring sesuai dengan gradasinya di cuci terlebih dahulu sebelum digunakan untuk campuran mortar. Pencucian pasir batanghari tersebut sampai air yang digunakan tersebut bersih dari kotoran.

3. Pasir yang di bersihkan dengan larutan $\mathrm{NaOH} 3 \%$

Pasir yang sudah disaring, direndam dengan larutan $\mathrm{NaOH} 3 \%$ kemudian dibiarkan selama 24 jam. Setelah itu dicuci dengan air sampai bersih.

\section{HASIL DAN PEMBAHASAN}

\section{Kadar Lumpur}

Hasil uji kadar lumpur untuk ketiga perlakuan pasir adalah sebagai berikut:

Tabel 4. Hasil pengujian kadar lumpur

\begin{tabular}{lc}
\hline Perlakuan & Kadar lumpur \\
\hline pasir tidak dicuci & $0,88 \%$ \\
pasir dicuci dengan air & $0,26 \%$ \\
No. 4 pasir yang direndam $\mathrm{NaOH} 3 \%$ & $0,00 \%$ \\
\hline
\end{tabular}

Sumber : Data Olahan 2020

\section{Pengujian Analisa Saringan}

Tabel 5. Hasil Analisa Saringan Pasir Sungai Batanghari

\begin{tabular}{crrrrr}
\hline $\begin{array}{c}\text { Ukuran } \\
\text { Saringan } \\
\text { (Nomor) }\end{array}$ & $\begin{array}{c}\text { Berat Tertinggal } \\
\text { Tiap Saringan } \\
\text { (Gram) }\end{array}$ & $\begin{array}{c}\text { Jumlah Kumulatif } \\
\text { Berat Tertinggal } \\
(\text { Gram) }\end{array}$ & $\begin{array}{c}\text { Persentase } \\
\text { Jumlah } \\
\text { Tertinggal (\%) }\end{array}$ & $\begin{array}{c}\text { Persentase } \\
\text { Jumlah } \\
\text { Melalui (\%) }\end{array}$ & $\begin{array}{c}\text { Pasir Zona } \\
\text { IV }\end{array}$ \\
\hline $3 / 8$ & 0,0 & 0,0 & 0.00 & 100,00 & 100 \\
4 & 0,00 & 0,0 & 0.00 & 100,00 & $95-100$ \\
8 & 68,75 & 68,75 & 5,00 & 95,00 & $80-100$ \\
16 & 412,50 & 481,25 & 35,00 & 65,00 & $50-85$ \\
30 & 481,25 & 962,50 & 70,00 & 30,00 & $25-60$ \\
50 & 275,00 & 1237,50 & 90,00 & 10,00 & $5-30$ \\
100 & 137,50 & 1375,00 & 100,00 & 0,00 & $0-10$ \\
Pan & 0,00 & 0,00 & 0,00 & 0,00 & - \\
\hline
\end{tabular}

Sumber : Data Olahan 2020

Modulus Kehalusan $=\frac{5+35+70+90+100}{100}=3,00$

\section{Hasil Pengujian Kotoran Organik Dalam Pasir}

Pengujian menggunakan pasir kasar sungai Batanghari yang sudah kering oven. Dari hasil pengujian kotoran organik yang direndam 24 jam, warna larutan $\mathrm{NaOH} 3 \%$ setelah bereaksi dengan pasir kasar sungai Batanghari memiliki standar warna no. 5, warna cairan coklat tua pasir tidak dapat digunakan. Hal tersebut menunjukkan bahwa pasir kasar sungai Batanghari mengandung kotoran organik yang dapat mempengaruhi mutu mortar.

Pada pengujian ini sebelumnya pasir dicuci sampai bersih lalu dikeringkan dengan oven. Dari hasil pengujian kotoran organik yang direndam 24 jam, warna larutan $\mathrm{NaOH} 3 \%$ setelah bereaksi dengan pasir kasar sungai Batanghari memiliki standar warna nomor 3, warna cairan merah kekuning-kuningan yang artinya pasir bias digunakan untuk lantai biasa. Hal tersebut menunjukkan bahwa pasir kasar sungai Batanghari mengandung kotoran organik yang dapat mempengaruhi mutu mortar. Pasir direndam $\mathrm{NaOH} 3 \%$ selama 24 jam lalu dicuci sampai bersih, lalu dikeringkan dengan oven. Dari hasil pengujian kotoran organik yang direndam 24 jam, warna larutan $\mathrm{NaOH} 3 \%$ setelah bereaksi dengan pasir kasar sungai Batanghari memiliki standar warna nomor 1, warna cairan tidak ada warna sampai dengan warna kuning muda pasir dapat digunakan.

\section{Desain Campuran}

\section{Desain campuran Standar}

Sesuai SNI 03-6825-2020 untuk membuat 6 buah benda uji dibutuhkan komposisi campuran sebagai berikut:

1. Semen $=500$ gram

2. Pasir silika $=1375$ gram

3. Air $=242 \mathrm{ml}$ 
Pada penelitian ini pasir yang digunakan adalah pasir halus sungai Batanghari, dan ada tiga perlakuan pasir untuk masing-masing mortar yang dibuat. Maka desain campuran tersebut harus disesuaikan hingga persyaratan flow untuk mortar yang dibuat terpenuhi. Jumlah air pada campuran dikontrol sehingga flow terpenuhi. Benda uji mortar dibuat sebanyak 6 buah untuk setiap kali pencampuran, sehingga nilai flow yang diperoleh adalah untuk setiap 6 benda uji.

\section{Desain Campuran Benda Uji dan Nilai Flow}

Setelah beberapa kali percobaan pendahuluan didapatkan penambahan air sebanyak 9,5\% dari jumlah air awal menghasilkan nilai flow dalam kriteria yang ditetapkan. Berikut ini adalah komposisi campuran untuk 6 benda uji mortar untuk masing-masing perlakuan pasir:

Tabel 6. Desain campuran komposisi mortar dan nilai flow

\begin{tabular}{lcccc}
\hline \multicolumn{1}{c}{ Jenis Perlakuan Pasir } & $\begin{array}{c}\text { Semen } \\
\text { (gram) }\end{array}$ & Pasir (gram) & $\begin{array}{c}\text { Air } \\
(\mathbf{m l})\end{array}$ & Nilai flow (\%) \\
\cline { 2 - 5 } tidacuci (PTD) & 500 & 1375 & 217,80 & 112,24 \\
dicuci air (PDC) & 500 & 1375 & 212,96 & 111,27 \\
direndam NaOH 3\% $(\mathrm{PNaOH})$ & 500 & 1375 & 212,96 & 113,07 \\
\hline
\end{tabular}

Sumber : Data Olahan 2020

\section{Hasil Pengujian Kuat Tekan Mortar}

Tabel 7. Kuat Tekan Rata-Rata Mortar $\left(\mathrm{kg} / \mathrm{cm}^{2}\right)$

\begin{tabular}{cccc}
\hline \multirow{2}{*}{ umur (hari) } & \multicolumn{3}{c}{ Perlakuan } \\
\cline { 2 - 4 } & PTD & PDC & PNaOH \\
\hline 7 & 250,78 & 315,86 & 391,07 \\
14 & 289,68 & 330,41 & 393,72 \\
28 & 369,65 & 394,33 & 459,07 \\
\hline
\end{tabular}

Sumber : Data Olahan 2020

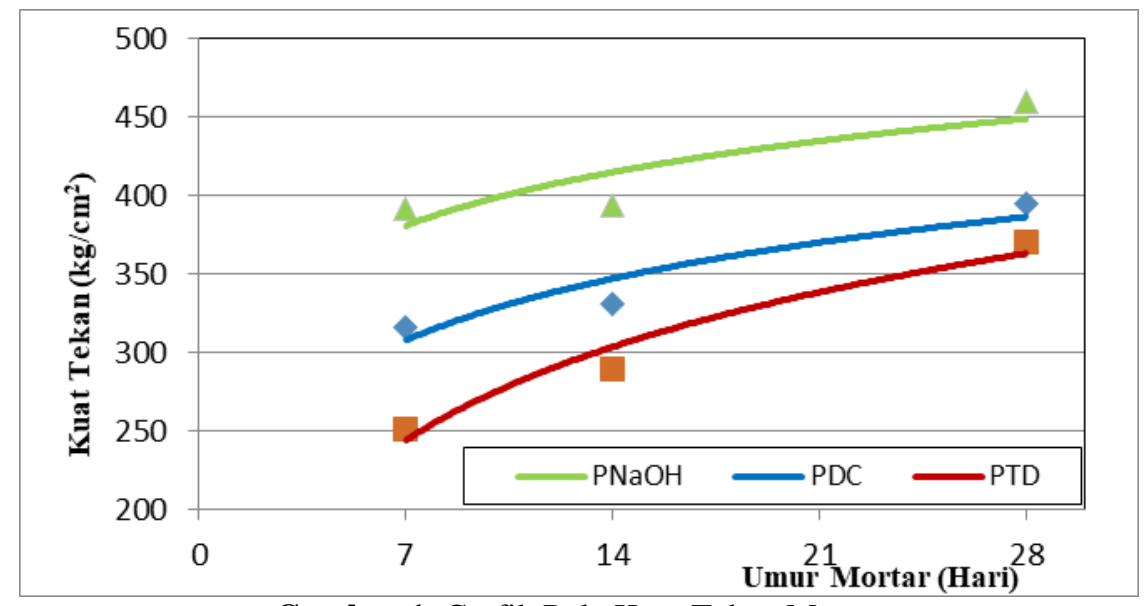

Sumber : Data Olahan 2020

Gambar 1. Grafik Pola Kuat Tekan Mortar

\section{SIMPULAN}

Dari hasil penelitian dan analisa yang telah dilakukan dapat diambil beberapa kesimpulan sebagai berikut:

1. Kuat tekan mortar pasir tidak dicuci umur 7 hari adalah $250,78 \mathrm{~kg} / \mathrm{cm}^{2}$ sedangkan umur 14 hari adalah $289,68 \mathrm{~kg} / \mathrm{cm}^{2}$ dan pada umur 28 hari mencapai $369,65 \mathrm{~kg} / \mathrm{cm}^{2}$.

2. Kuat tekan mortar pasir yang dicuci dengan air umur 7 hari adalah $315,86 \mathrm{~kg} / \mathrm{cm}^{2}$ sedangkan umur 14 hari adalah $330,41 \mathrm{~kg} / \mathrm{cm}^{2}$ dan pada umur 28 hari mencapai $394,33 \mathrm{~kg} / \mathrm{cm}^{2}$ serta persentase kenaikan mortar umur 28 hari adalah $6,67 \%$ kenaikan nilai kuat tekan dibandingkan pasir tidak dicuci.

3. Kuat tekan mortar pasir yang direndam dengan $\mathrm{NaOH} 3 \%$ umur 7 hari adalah $391,07 \mathrm{~kg} / \mathrm{cm}^{2}$ sedangkan umur 14 hari adalah $393,72 \mathrm{~kg} / \mathrm{cm}^{2}$ dan pada umur 28 hari mencapai $459,07 \mathrm{~kg} / \mathrm{cm}^{2}$ serta persentase kenaikan mortar umur 28 hari adalah 24,19\% kenaikan nilai kuat tekan dibandingkan pasir tidak dicuci.

4. Dari semua hasil kuat tekan mortar, pengujian mortar pasir yang direndam dengan $\mathrm{NaOH} 3 \%$ menunjukan nilai kuat tekan yang lebih tinggi dari pasir tidak dicuci dan pasir yang dicuci dengan air. 
Maidita Ajizah Prastika, Suhendra dan Wari Dony, Pengaruh Kotoran Organik pada Pasir Kasar Sungai Batanghari terhadap Kuat Tekan Mortar

5. Kandungan Organik pada pasir dapat mempengaruhi presentase kenaikan kuat tekan

\section{DAFTAR PUSTAKA}

ASTM C-33. Standard Specification for Concrete Aggregates.

ASTM C-305. Mechanical Mixing of Hydraulic Cement Pastes and Mortars of Plastic Consistency.

British Standard 812-1976. Testing aggregates.

Neville, Adam M. 2011. Properties of concrete. $5^{\text {th }}$ ed. Pearson Education Limited. England

Nugraha dan Antoni. 2007. Teknologi Beton. Yokyakarta: ANDI Yogyakarta

SK SNI S 04-1989-F. Spesifikasi Agregat Sebagai Bahan Bangunan. Yayasan LPMB. Bandung

SNI 03-1750-1990. Agregat beton, Mutu dan cara uji. Badan Standardisasi Nasional (BSN).

SNI 03-6825-2002 Metode Pengujian Kekuatan Tekan Mortar Semen Portland Untuk Pekerjaan Sipil. Badan Standardisasi Nasional (BSN).

SNI 03-6882-2002. Spesifikasi Mortar Untuk Pekerjaan Unit Pasangan. Badan Standardisasi Nasional (BSN).

SNI 06-6989-11-2004. Air dan air limbah - Bagian 11: Cara uji derajat keasaman (pH) dengan menggunakan alat pH meter. Badan Standardisasi Nasional (BSN).

SNI 15-7064-2004. Semen Portland Komposit. Badan Standardisasi Nasional (BSN).

SNI 7656-2012. Tata Cara Pemilihan Campuran Beton Normal, Beton Berat, dan Beton Massa. Badan Standardisasi Nasional (BSN).

SNI 03-2847-2013 Persyaratan beton struktural untuk bangunan gedung. Badan Standardisasi Nasional (BSN).

SNI 2816 : 2014. Metode Uji bahan organik dalam agregat halus untuk beton. Badan Standardisasi Nasional (BSN).

Tjokrodimulyo K. 2012. Teknologi Beton. Yogyakarta. KMTS FT UGM.

Tri Mulyono. 2004. Teknologi Beton. ANDI Yogyakarta. Yogyakarta 